\title{
Antiproliferative Effects of Free and Encapsulated Hypericum Perforatum L. Extract and Its Potential Interaction with Doxorubicin for Esophageal Squamous Cell Carcinoma
}

\author{
Issa Amjadi', Mohammad Mohajeri², Andrei Borisov ${ }^{3}$, Motahare-Sadat Hosseini' ${ }^{4 *}$ \\ ${ }^{1}$ Department of Biomedical Engineering, Wayne State University, Detroit, United States \\ 2 Department of Medical Biotechnology, Mashhad University of Medical Sciences, Mashhad, Iran \\ ${ }^{3}$ Department of Biomedical Engineering, Wayne State University, Detroit, United States \\ ${ }^{4}$ Biomaterials Group, Department of Biomedical Engineering, Amirkabir University of Technology, Tehran, Iran
}

\section{Key Words}

doxorubicin, hypericum perforatum extract, nanoparticles, esophageal squamous cell carcinoma, drug resistance

\section{Abstract}

Objectives: Esophageal squamous cell carcinoma (ESCC) is considered as a deadly medical condition that affects a growing number of people worldwide. Targeted therapy of ESCC has been suggested recently and required extensive research. With cyclin Dl as a therapeutic target, the present study aimed at evaluating the anticancer effects of doxorubicin (Dox) or Hypericum perforatum L. (HP) extract encapsulated in poly(lactic-co-glycolic acid) (PLGA) nanoparticles on the ESCC cell line KYSE30.

Methods: Nanoparticles were prepared using double emulsion method. Cytotoxicity assay was carried out to measure the anti-proliferation activity of Dox-loaded (Dox NPs) and HP-loaded nanoparticles (HP NPs) against both cancer and normal cell lines. The mRNA gene expression of cyclin D1 was evaluated to validate the cytotoxicity studies at molecular level.

Received: Aug 06, $2018 \quad$ Reviewed: Feb 13, 2019 Accepted: May 20, 2019

$@$ This is an Open-Access article distributed under the terms of the Creative Common Attribution Non-Commercial License (http://creativecommons.org/licenses/by-nc/4.0/) which permits unrestricted noncommercial use, distribution, and reproduction in any medium, provided the original work is properly cited.

( This paper meets the requirements of KS X ISO 9706, ISO 9706-1994 and ANSI/NISO Z39.48-1992 (Permanence of Paper).
Results: Free drugs and nanoparticles significantly inhibited KYSE30 cells by $55-73 \%$ and slightly affected normal cells up to $29 \%$. The $\mathrm{IC}_{50}$ of Dox NPs and HP NPs was $\sim 0.04-0.06 \mathrm{mg} / \mathrm{mL}$ and $\sim 0.6-0.7 \mathrm{mg} / \mathrm{mL}$, respectively. Significant decrease occurred in cyclin D1 expression by Dox NPs and HP NPs $(\mathrm{P}<0.05)$. Exposure of KYSE-30 cells to combined treatments including both Dox and HP extract significantly increased the level of cyclin D1 expression as compared to those with individual treatments $(\mathrm{P}<0.05)$.

Conclusion: Dox NPs and HP NPs can successfully and specifically target ESCC cells through downregulation of cyclin D1. The simultaneous use of Dox and HP extract should be avoided for the treatment of ESCC.

\section{Introduction}

Cancer is described as a disease where a group of tumor types are developed through an uncontrolled growth of abnormal cells. Upon the rapid growth, pathological outcomes such as tissue fractures are established which cannot be overcome by normal cells. Cancer constitutes the second cause of death across the globe and its incidence is steadily on the rise [1, 2]. Esophageal cancer is a male-dominant aggressive malignancy, while ranking eighth among cancers and sixth in mortality $[3,4]$. It has two most-common types, including squamous cell carcinoma and ade- 
nocarcinoma [5]. The former (i.e., esophageal squamous cell carcinoma; ESCC) is primarily reported from Asia [6]. In spite of progress in surgical resection and adjuvant chemoradiotherapy, affected patients still tend to have poor prognoses. Although, there are individual differences in ESCC formation, determination of gene expression in response to certain anticancer drugs could promote the design of targeted ESCC therapy [7]. Cyclin D1 appears to be mostly enhanced and over-expressed in ESCC, suggesting that it acts as a central player in the disease. Indeed, cyclin D1 amplification induces tumorigenesis as well as tumor growth [8].

To treat both localized and metastasized cancers, the main therapeutic approach is chemotherapy [2, 9, 10], whereby specialized medicines with anticancer properties are infused through the blood vessels [11]. Recently, several clinically active anticancer drugs have been created and used for this purpose. The majority of cancer drugs fail to distinguish between cancer cells and normal cells that culminates in adverse effects and deleterious reactions in tissues [10]. Targeted drug delivery is a process that a specific biomolecular agent is engineered to release with the purpose of improving product efficacy as well as patient safety $[12,13]$. To this aim, many polymeric materials have been studied to encapsulate the drug and release it in a controlled fashion $[11,14,15]$. Additionally, a drug delivery system based on polymers is more likely to minimize these side effects [15], and it may enhance drug distribution in the body, augment the drug specificity, extend the duration of drug activity and ameliorate in vivo degradation resistance [16]. In this regard, the encapsulation of anticancer agents into nanoparticles (NPs) has garnered much global attention. Doxorubicin (Dox) is a widely used drug with anticancer activities, chiefly administered for the treatment or management of solid tumors [17]. Dox-induced toxicity and resistance are the major drawbacks in chemotherapy and clinical practice [18]. Current evidence shows that it produces chemically reactive molecules containing oxygen, able to trigger a series of unprecedented reactions that involve the heart, kidney, liver, brain, and reproductive organs [18]. More to the point, Dox has the ability to enter target cells through cellular membranes without taking advantage of distinct transporters owning to its hydrophobic nature. However, active efflux of the drug reduces its content inside cells by means of ATP-dependent efflux transporters. This event is described as multidrug resistance that cancer cells resist against the cytotoxicity caused by chemotherapeutic drugs [18].

Hypericum perforatum L. (St. John's Wort; HP) is a complex herbaceous drug from the Hypericaceae species [19] that contains a variety of anticancer components, including hypericin, $\alpha$-terpineol, betacarotene, caffeic acid, isoquercitin, kaempferol, gallic acid, limonene, rutin, and vanillic acid [13]. It was traditionally applied for the treatment of anxiety, depression, insomnia, water retention, and gastritis. Also, HP extracts seem to decline oxidative stress, thereby inhibiting neurotoxicity, inflammation, and gastrointestinal issues [20]. Rats treated with doses of HP were found to decrease levels of blood and bowel enzymes related to colonic inflammation [21], and have a lower prevalence of gastric ulcers [22]. Quercetin and I3,II8-biapigenin, known as the two main oil extracts of HP, demonstrated special anti-inflammatory and gastroprotective actions [23]. More recently, a case report by Karaarslan et al. provided a perspective on the anti-tumor properties of HP with possible mechanisms and pathological evidence in three patients with gastrointestinal cancer. They observed long-term HP use, extensive host reaction, and tendency to develop barrier against tumor that can denote a morphological sign of its anti-tumor response [24].

In our previous studies on a nanoparticle drug delivery system, two different formulations were developed using Dox and HP as anticancer agents. The results indicated that both drugs can be successfully loaded in the polymeric carriers made up of poly(lactic-co-glycolic acid) (PLGA) $[13,25]$. The present study was intended to investigate the anticancer effects of these two complexes in an in vitro model of ESCC (KYSE-30 cells).

\section{Materials and Methods}

\subsection{Chemicals}

Dox hydrochloride and PLGA 50:50 were respectively purchased from Sigma Chemical Company (USA) and Boehringer Ingelheim (Germany). Dichloromethane (DCM) and fully hydrolyzed (99.8\%) poly vinyl alcohol (PVA; $\mathrm{Mn}=72000 \mathrm{~g} / \mathrm{mol}$ and $99.8 \%$ hydrolysis) were purchased from Merck (Germany) without further purification. The HP extract was graciously provided by Prof. Sefidkon (Research Institute of Forests and Rangelands, Tehran, Iran).

\subsection{Nanoparticle preparation}

Initially, HP extract (10 mg) was mixed with $5 \mathrm{~mL}$ of $70 \%$ methanol under constant stirring in a water bath at $60^{\circ} \mathrm{C}$ until it was completely dissolved. The other inner aqueous phase was Dox used at the same concentration of HP extract. Nanoparticles were prepared using the (should be omitted) double emulsion method, which was previously published. The drugs were emulsified in $50 \mathrm{mg}$ of PLGA in $50 \mathrm{~mL}$ of DCM by sonication for $2 \mathrm{~min}$. Afterwards, the solution was added to $3 \%$ PVA to form secondary emulsion. After solvent evaporation, the particles were subjected to centrifugation [13]. The size of resultant nanoparticles with spherical morphology ranged between 100 and $400 \mathrm{~nm}$ (data not shown), which was consistent with our previous reports $[13,25]$.

\subsection{Cell lines}

Two cancerous and normal cell lines were used in this study: the human esophageal squamous cell carcinoma cells (KYSE-30; Cat No: 94072011) and normal cells (Cat No: 85120602). They were purchased from the Cell Bank, Pasteur Institute of Iran (Tehran, Iran). The second one served as the control group. The DMEM (Gibco, Germa- 
ny) supplemented with $10 \%$ FBS (GIBCO, Germany), penicillin $(1 \% \mathrm{v} / \mathrm{v})$, and streptomycin $(1 \% \mathrm{v} / \mathrm{v})$ was utilized to maintain the cells in an incubator set at $37^{\circ} \mathrm{C}$ and $5 \% \mathrm{CO}_{2}$.

\subsection{Determination of cell viability}

The cytotoxicity induced by Dox-loaded PLGA nanoparticles (Dox NPs), Dox, HP-loaded PLGA nanoparticles (HP NPs), and HP extract was measured by the 3-(4,5-dimethylthiazol-2-yl)-2,5-diphenyltetrazolium bromide (MTT) assay (Sigma, USA). Briefly, KYSE-30 and normal cells $(5000$ cells $/ \mathrm{mL}$ ) were cultured in every well of 96 -well plates (BD Biosciences, USA) containing $100 \mu \mathrm{L}$ of DMEM medium. Following incubation for $48 \mathrm{~h}$, the cells were exposed to different concentrations of loaded nanoparticles and free drugs in triplicate and subsequently kept in an incubator for $24 \mathrm{~h}$. A certain amount of $5 \mathrm{mg} / \mathrm{mL}$ MTT solution was added to each well to reach the final concentration of $0.5 \mathrm{mg} / \mathrm{mL}$ prior to an extra incubation for $3.5 \mathrm{~h}$ at $37^{\circ} \mathrm{C} .200 \mu \mathrm{L}$ of dimethyl sulfoxide (DMSO; Sigma, USA) was used to dissolve the formazan precipitate. The optical density was read employing an ELISA plate reader (Organon Teknika, Netherlands) at a wavelength of $490 \mathrm{~nm}$. The $\mathrm{IC}_{50}$ was calculated as $\mathrm{mg} / \mathrm{mL}$.

\section{5. mRNA Gene expression of Cyclin D1}

The cells were treated with NPs and free drugs at $\mathrm{IC}_{50}$ as follows: KYSE-30 + Dox (S1); KYSE-30 + Dox NPs (S2); KYSE-30 + HP (S3); KYSE-30 + HP NPs (S4); KYSE-30 + Dox + HP (S5); KYSE-30 + Dox + HP NPs (S6); KYSE-30 + HP + Dox NPs (S7); normal cells + Dox NPs (S8); normal cells + HP NPs (S9); KYSE-30 (S10). RNA from the cultured cells was isolated by an RNA extraction kit (Roche, Cat No: 11828665001). All steps were performed according to instructions in an RNase/DNase free environment. The quality of the RNA samples was confirmed by electrophoresis through agarose gels. cDNA was synthesized from the RNA extracts ( $10 \mathrm{ng}$ ) by a cDNA reverse transcription kit (Parstous Co., Tehran, Iran). A quantitative real-time polymerase chain reaction (PCR) assay was conducted using the next primers sequences: GAPDH: 5' GGATGCTGGAGGTCTGCGAGGAAC 3' (forward) and 5' GAGAGGAAGCGTGTGAGGCGGTAG 3' (reverse); cyclin D1: 5' TGCACCACCAACTGCTTAGC 3' (forward) and 5' GGCATGGACTGTGGTCATGAG 3' (reverse). The quantitative RT-PCR cycling was: $95^{\circ} \mathrm{C}$ for $30 \mathrm{~s}$; $\left[95^{\circ} \mathrm{C}\right.$ for $\left.4 \mathrm{~s}\right] \times 45$ cycles; $\left[60^{\circ} \mathrm{C}\right.$ for $\left.32 \mathrm{~s}\right] \times 45$ cycles, for melting curve: $95^{\circ} \mathrm{C}$ for 10 s; $60^{\circ} \mathrm{C}$ for $60 \mathrm{~s}$. The $2-\Delta \Delta \mathrm{Ct}$ values were calculated for all samples. Relative changes in gene expression were determined and then normalized to the corresponding reference gene (GAPDH) levels.

\subsection{Statistical Analysis}

Experiments were done in triplicate and the obtained data were collected and fed into SPSS (24.0 version, IBM Inc., USA). The results were expressed as means \pm standard deviation (SD). Statistical analyses included Student's t-test or one-way analysis of variance (ANOVA) to deter- mine a significant difference at P-values $<0.05$.

\section{Results}

\subsection{Growth Inhibition of KYSE-30 Cells by Nanoparticles and Free Drugs}

KYSE-30 and normal squamous cells were treated with free Dox, Dox NPs, free HP extract, and HP NPs in varying concentrations for $24 \mathrm{~h}$. The results of MTT assay are demonstrated in Figure 1. Overall, all treatments inhibited cell viability in a dose-dependent fashion. Upon administration of Dox NPs and HP NPs, the count of KYSE-30 cell line respectively reduced by $73.0 \%$ and $71.8 \%$, which were greater than their free drugs (55.9\% and $57.1 \%)$, however normal cell line were affected to a lesser degree $(<29 \%$ for concentrations below $\mathrm{IC}_{50}$ and $<17 \%$ for concentrations above $\mathrm{IC}_{50}$ ), suggesting the effective and selective action of nanoparticles only against cancerous cells. Noteworthy, both free HP extract and HP NPs exerted their anticancer impacts at higher concentrations than those of free Dox and Dox NPs. Also, as the concentration of Dox NPs and HP NPs lifted, the viability of KYSE-30 cells diminished significantly $(\mathrm{P}<0.05)$ while that of normal cells showed a slight reduction $(\mathrm{P}>0.05)$. The $\mathrm{IC}_{50}$ of Dox and HP extract was $\sim 0.090-0.095 \mathrm{mg} / \mathrm{mL}$ and $\sim 0.92-0.94 \mathrm{mg} / \mathrm{mL}$ in KYSE30 cells. Considering the entrapment efficiency of $48 \%$ and $21 \%$ for Dox-loaded and HP-loaded nanoparticles, higher contents of the initial drug loading (approximately twice for Dox and five times for HP extract) were used to encapsulate into PLGA to evaluate in vitro anticancer activity of these complexes. The finding indicated that Dox NPs and HP NPs achieved the inhibitory rate of $50 \%$ at the initial drug loading of $\sim 0.08-0.12 \mathrm{mg} / \mathrm{mL}$ and $\sim 3-3.5 \mathrm{mg} / \mathrm{mL}$ in KYSE-30 cells. This effect was produced by $\sim 0.04-0.06 \mathrm{mg} /$ $\mathrm{mL}$ of Dox and $\sim 0.6-0.7 \mathrm{mg} / \mathrm{mL}$ of HP extract entrapped into the polymeric carrier, which were significantly lower than those of the free drugs in KYSE-30 $(\mathrm{P}<0.05)$. This mirrored the improved cytotoxicity of free drugs in nanoparticles.

\subsection{Down-regulation of Cyclin D1 Gene Ex- pression in KYSE-30 Cells}

The mRNA gene expression of cyclin D1 is presented in Figure 2. Significant reduction of cyclin D1 expression was observed after exposure of KYSE-30 cells to Dox NPs (S2) and HP NPs (S4) as respectively compared with Dox $(\mathrm{S} 1 ; \mathrm{P}=0.012)$ and HP extract (S3; P = 0.033). Moreover, combined treatments of KYSE-30 cells with Dox and HP extract (S5), Dox and HP NPs (S6), and HP extract and Dox NPs (S7) significantly enhanced the level of cyclin D1 expression in comparison with individual treatments (S1, S2, S3, and S4; P < 0.05), suggesting that the presence of HP extract, either in the form of nanoparticles or free drug, could decrease Dox concentrations below the therapeutic range. Given the samples S8 and S9 in relation to samples S2 and S4, it was found that cyclin D1 expression levels in normal cells were at least 2-fold of those in cancerous cells $(\mathrm{P}<0.05)$. 

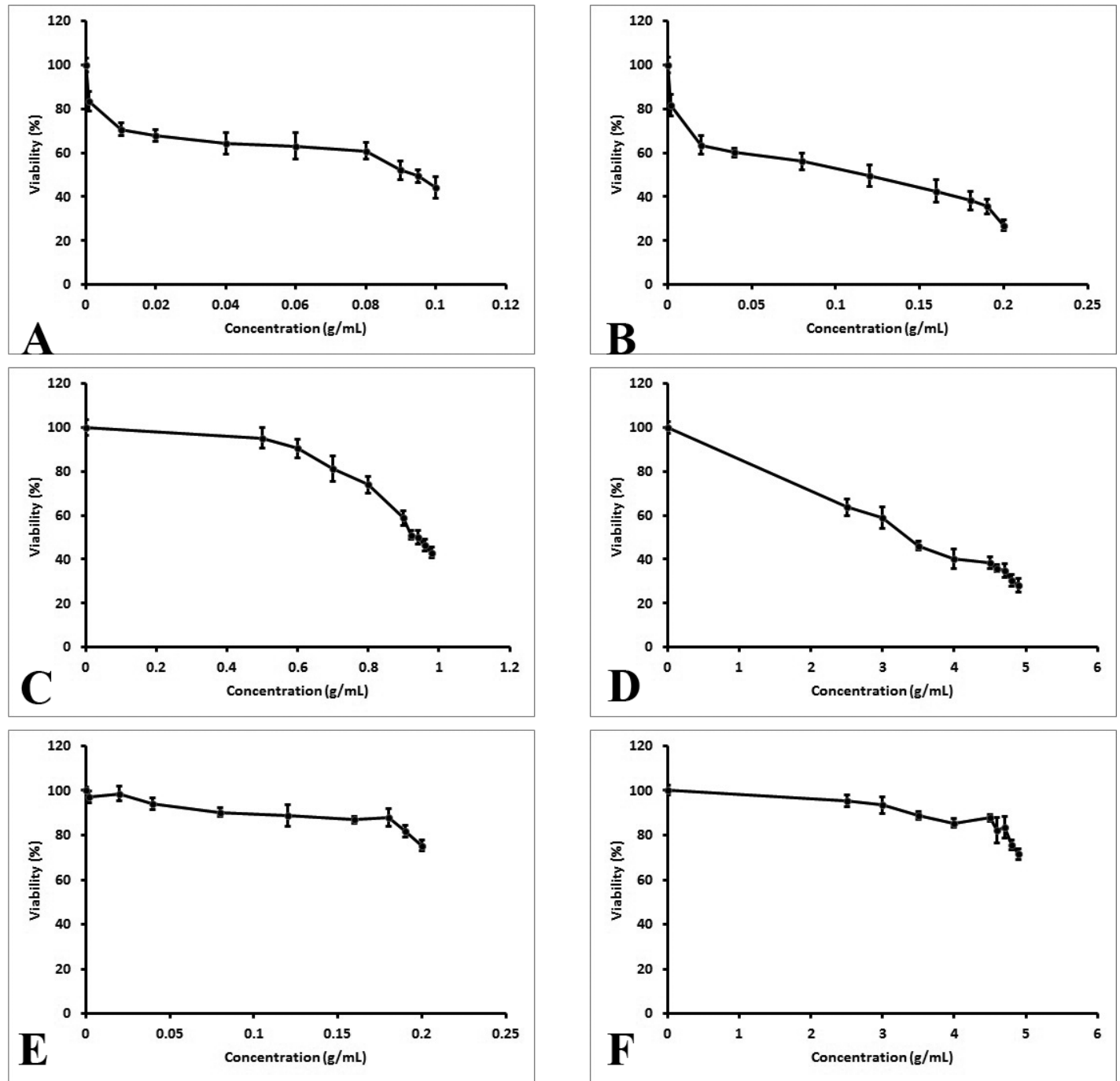

Figure 1 Effects of Dox and HP extract on KYSE-30 and normal cells: (A) cytotoxicity of Dox in KYSE-30 cells; (B) cytotoxicity of Dox NPs in KYSE-30 cells; (C) cytotoxicity of HP extract in KYSE-30 cells; (D) cytotoxicity of HP NPs in KYSE-30 cells; (E) cytotoxicity of Dox NPs in normal cells; (F) cytotoxicity of HP NPs in normal cells.

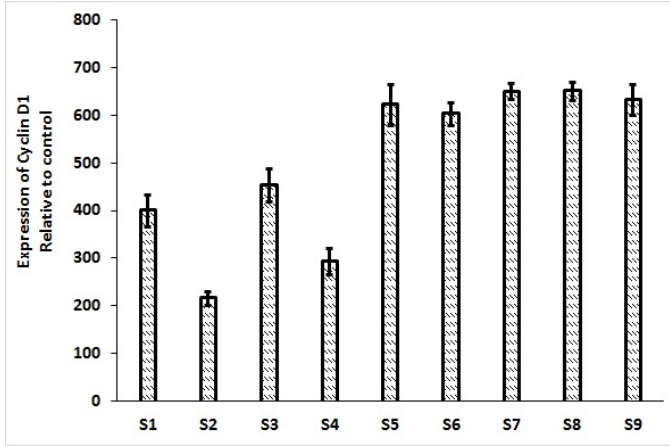

Figure 2 Expression of cyclin D1 in the cancer cells treated with the seven samples [S1 (Dox), S2 (Dox NPs), S3 (HP extract), S4 (HP NPs), S5 (Dox and HP extract), S6 (Dox and HP NPs) and S7 (HP extract and Dox NPs)], and in normal cells treated with the two samples [S8 (Dox NPs) and S9 (HP NPs)].

\section{Discussion}

Dox-induced toxicity and resistance are more likely to occur upon the interactions between Dox and target tissue, which respectively arise from reactive oxygen species generation and high cumulative dose [18]. On one hand, the major side effects of Dox have been documented in the heart and are associated with changes in biochemical markers and histopathological parameters [26]. On the other hand, resistance of cancer cells to Dox can be related to loss in drug accumulation in the nucleus, decreased DNA damage, and suppression of the downstream events led to apoptosis [18]. In this regard, ATP-binding cassette transporters have attracted much attention concern- 
ing poor response to chemotherapy that hinders clinical progress in the treatment or management of cancer [27]. These two obstacles necessitate the application of targeted drug delivery systems or other natural agents with anticancer activities. To overcome these complexities, many delivery systems have been proposed to promote the efficacy of Dox-based chemotherapy. For example, a polymeric carrier was developed using different compositions of PLGA in an in vitro study. It was reported that glycolide content as well as sonication method had a considerable potential to control over Dox solubility and cumulative release rate. Both PLGA hydrophilicity and Dox loading were found to be responsible for the drug targeting, blood clearance, and cytotoxicity in mouse fibrosarcoma cells (L929) [25].

As another alternative, recent studies have shifted towards the use of plant species. Herbal medicines and supplements have achieved notable popularity worldwide, which, in turn, elevates the probability of herb-drug interactions [28]. Indeed, they are able to enhance or diminish an expected action of administered drugs, inducing either treatment failure or unwanted adverse effects [29]. The use of HP supplements is on the rise, particularly among people as an anti-depressant [30]. Existing evidence also shows the other medicinal features of HP, such as an antimicrobial effect [31], wound healing activity [32], hypolipidemic action [33], positive contribution to inflammatory bowel diseases [21], treatment of opium dependence [34], anticancer potential [35], antioxidant effect, and neuroprotective potential [36]. However, its action against other types of cancer diseases warrants further investigation. More to the point, there have been some reports that numerous drugs have an interaction with HP, namely antidepressants, anticonvulsants, immunosuppressants, contraceptives, anti-HIV, anticancer, and cardiovascular drugs [37,38]. Therefore, its biological interaction with other biomolecules has yet to be explored.

In the present study, the effectiveness of Dox NPs and HP NPs was examined for ESCC. The findings displayed that the anti-proliferation properties of free Dox and HP extract were ameliorated against KYSE-30 cells upon nanoencapsulation, which might be modulated through the down-regulation of cyclin D1 gene expression. Furthermore, nanoparticles caused a significant increase in cytotoxicity and yet decrease in the $\mathrm{IC}_{50}$ values in KYSE-30 cells. Interestingly, the presence of HP extract impeded the suppression of cyclin D1 gene expression associated by Dox administration. To the best of our knowledge, this is the first study indicating the effectiveness of nanoparticles containing Dox and HP extract for ESCC and the interaction of Dox and HP extract in vitro. The anti-proliferation activity of Dox against human esophageal squamous cancer cells was previously investigated by Lee et al. in a different cellular model (TE-12 cells) [39]. They indicated that G2/M cell cycle arrest and apoptosis in human ESCC cells were stimulated in response to Dox. These events took place after the suppression of Akt phosphorylation [39]. What is more, Dox has appeared to repress glutathione S-transferase activity [40] and lower the content of cytochrome P450 [41, 42]. By contrast, it has been observed that administration of HP for 10 days in rats augmented the levels of multidrug resistance protein 2, glutathione S-transferase-P, and cytochrome P450 $1 \mathrm{~A} 2$ by $304 \%, 252 \%$ and $357 \%$, respectively [ 43$]$. Thus, the counteraction between Dox and HP might be justified by their opposite effects on glutathione S-transferase and cytochrome P450. In line with this result, some studies have addressed similar issues with other anticancer agents. For example, the metabolization of imatinib is mainly performed by CYP3A4 however the enzymes CYP2D6, CYP1A2, CYP2C9, and CYP2C19 can be also involved. The consumption of $\mathrm{HP}$ at the same time has been shown to mitigate the bioavailability, half-life, and of $\mathrm{C}_{\max }$ of a single dose of imatinib but elevate its oral clearance following the 14-day intake of HP in healthy volunteers $[44,45]$. Irinotecan is known as a prodrug metabolized by means of CYP3A4. CYP3A4-induction by HP had lowering impacts on the plasma concentration of irinotecan metabolites, neutrophils, lymphocytes, as well as platelets [46]. Docetaxel, a semisynthetic taxane, is converted to its metabolites by CYP3A4 and CYP2C8. The simultaneous administration of HP with docetaxel was reported to attenuate the bioavailability, half-life, and $\mathrm{C}_{\max }$ of docetaxel in ten patients with cancer, increase clearance, and finally reduce the adverse effects of the docetaxel [47]. Paclitaxel is described as another anticancer taxane, whose metabolism is primarily mediated by CYP2C8 and CYP3A4 in the liver [48]; hence, HP has the ability to alter its pharmacokinetics. Dox as an anticancer agent with substrates of CYP enzymes is expected to negatively interact with co-administration of HP, as exhibited by the suppression of cyclin D1 activity.

In conclusion, this study indicated anticancer potential of HP extract against esophageal cancer cells for the first time. Also, it highlighted the improved anti-proliferation activity of Dox NPs and HP NPs against a cellular model of esophageal tumors. This action might be mediated through the downregulation of cyclin D1 gene. The co-treatment of cancer cells with HP extract, either in the form of nanoparticles or free drugs, resulted in poor response to Dox and then multidrug resistance that confirmed by significant up-regulation of cyclin D1 gene expression. Therefore, the simultaneous use of Dox and HP extract is not recommended.

\section{Acknowledgement}

Amirkabir University of Technology approved this study and had no role in the design and conduct of the study.

\section{Conflict of interest}

The authors declare that there is no conflict of financial interest.

\section{References}

1. Malek M, Aghili R, Emami Z, Khamseh ME. Risk of cancer in diabetes: the effect of metformin. ISRN endocrinology. 2013;2013:636927.

2. Yadav AK, Mishra P, Mishra AK, Mishra P, Jain S, Agraw- 
al GP. Development and characterization of hyaluronic acid-anchored PLGA nanoparticulate carriers of doxorubicin. Nanomedicine: Nanotechnology, Biology and Medicine. 2007;3(4):246-257.

3. Abbas G, Krasna M. Overview of esophageal cancer. Annals of cardiothoracic surgery. 2017;6(2):131-136.

4. Chen Z, Ren Y, Du XL, Yang J, Shen Y, Li S, et al. Incidence and survival differences in esophageal cancer among ethnic groups in the United States. Oncotarget. 2017;8(29):47037-47051.

5. Rafiemanesh H, Maleki F, Mohammadian-Hafshejani A, Salemi M, Salehiniya H. The trend in histological changes and the incidence of esophagus cancer in Iran (2003-2008). Int J Prev Med. 2016;7(1):31.

6. Enzinger PC, Mayer RJ. Esophageal cancer. The New England journal of medicine. 2003;349(23):2241-2252. Epub 2003/12/06.

7. Phukan RK, Ali MS, Chetia CK, Mahanta J. Betel nut and tobacco chewing; potential risk factors of cancer of oesophagus in Assam, India. British journal of cancer. 2001;85(5):661-667. Epub 2001/09/05.

8. Lin DC, Du XL, Wang MR. Protein alterations in ESCC and clinical implications: a review. Diseases of the esophagus. official journal of the International Society for Diseases of the Esophagus. 2009;22(1):9-20. Epub 2008/06/20.

9. Chidambaram M, Manavalan R, Kathiresan K. Nanotherapeutics to overcome conventional cancer chemotherapy limitations. Journal of pharmacy \& pharmaceutical sciences. 2011;14(1):67-77.

10. Chouhan R, Bajpai A. Real time in vitro studies of doxorubicin release from PHEMA nanoparticles. Journal of nanobiotechnology. 2009;7(1):5.

11. Bromberg L, Alakhov V. Effects of polyether-modified poly (acrylic acid) microgels on doxorubicin transport in human intestinal epithelial Caco-2 cell layers. Journal of controlled release. 2003;88(1):11-22.

12. Gupta RB, Kompella UB. Nanoparticle Technology for Drug Delivery. New York: Taylor and Francic; 2006.

13. Amjadi I, Rabiee M, Hosseini M, Sefidkon F, Mozafari M. Nanoencapsulation of Hypericum perforatum and doxorubicin anticancer agents in PLGA nanoparticles through double emulsion technique. Micro \& Nano Letters. 2013;8(5):243-247.

14. Bonakdar S, Poursamar SA, Rafienia M, Shokrgozar MA, Farhadi A, Hosseini M. Effect of Freezing and Thawing Process on Betamethasone Acetate Release from Polyvinyl alcohol Nanospheres. Solid State Phenomena. 2009;151:159-165.

15. Lebold T, Jung C, Michaelis J, Brauchle C. Nanostructured silica materials as drug-delivery systems for doxorubicin: single molecule and cellular studies. Nano letters. 2009;9(8):2877-2883.

16. Wong HL, Bendayan R, Rauth AM, Xue HY, Babakhanian K, Wu XY. A mechanistic study of enhanced doxorubicin uptake and retention in multidrug resistant breast cancer cells using a polymer-lipid hybrid nanoparticle system. Journal of Pharmacology and Experimental Therapeutics. 2006;317(3):1372-1381.

17. Yu D, Xiao S, Tong C, Chen L, Liu X. Dialdehyde starch nanoparticles: Preparation and application in drug car- rier. Chinese Science Bulletin. 2007;52(21):2913-2918.

18. Mohajeri M, Sahebkar A. Protective effects of curcumin against doxorubicin-induced toxicity and resistance: A review. Critical Reviews in Oncology/Hematology. 2018;122:30-51.

19. Soleymani S, Bahramsoltani R, Rahimi R, Abdollahi M. Clinical risks of St John's Wort (Hypericum perforatum) co-administration. Expert opinion on drug metabolism \& toxicology. 2017;13(10):1047-1062.

20. Klemow KM, Bartlow A, Crawford J, Kocher N, Shah J, Ritsick M. Chapter 11: Medical Attributes of St. John's Wort (Hypericum perforatum). In: Benzie I, Wachtel-Galor S, editors. Herbal Medicine: Biomolecular and Clinical Aspects. 2nd ed. Boca Raton (FL): CRC Press/Taylor \& Francis; 2011.

21. Dost T, Ozkayran H, Gokalp F, Yenisey C, Birincioglu M. The effect of Hypericum perforatum (St. John's Wort) on experimental colitis in rat. Dig Dis Sci. 2009;54(6):12141221.

22. Cayci MK, Dayioglu H. Hypericum perforatum extracts healed gastric lesions induced by hypothermic restraint stress in Wistar rats. Saudi Med J. 2009;30(6):750-754.

23. Zdunic G, Godevac D, Milenkovic M, Vucicevic D, Savikin K, Menkovic N, et al. Evaluation of Hypericum perforatum oil extracts for an antiinflammatory and gastroprotective activity in rats. Phytother Res. 2009;23(11):1559-1564.

24. Karaarslan S, Cokmert S, Cokmez A. Does St. John's Wort cause regression in gastrointestinal system adenocarcinomas? World Journal of Gastrointestinal Oncology. 2015;7(11):369-374.

25. Amjadi I, Rabiee M, Hosseini M-S. Anticancer activity of nanoparticles based on PLGA and its co-polymer: in-vitro evaluation. Iranian journal of pharmaceutical research: IJPR. 2013;12(4):623-634.

26. Takemura G, Fujiwara H. Doxorubicin-induced cardiomyopathy from the cardiotoxic mechanisms to management. Prog Cardiovasc Dis. 2007;49(5):330-352.

27. Cox J, Weinman S. Mechanisms of doxorubicin resistance in hepatocellular carcinoma. Hepatic oncology. 2016;3(1):57-59.

28. Zhou S, Chan E, Pan S-Q, Huang M, Lee EJD. Pharmacokinetic interactions of drugs with St John's wort. Journal of Psychopharmacology. 2004;18(2):262-276.

29. Bhadra R, Ravakhah K, Ghosh RK. Herb-drug interaction: The importance of communicating with primary care physicians. The Australasian medical journal. 2015;8(10):315-319.

30. Mannel M. Drug interactions with St John's wort. Drug safety. 2004;27(11):773-797.

31. Saddiqe Z, Naeem I, Maimoona A. A review of the antibacterial activity of Hypericum perforatum L. Journal of ethnopharmacology. 2010;131(3):511-521.

32. Öztürk N, Korkmaz S, Öztürk Y. Wound-healing activity of St. John's Wort (Hypericum perforatum L.) on chicken embryonic fibroblasts. Journal of ethnopharmacology. 2007;111(1):33-39.

33. Husain GM, Chatterjee SS, Singh PN, Kumar V. Hypolipidemic and antiobesity-like activity of standardised extract of Hypericum perforatum L. in rats. ISRN pharmacology. 2011;2011:505247. 
34. Feily A, Abbasi N. The inhibitory effect of Hypericum perforatum extract on morphine withdrawal syndrome in rat and comparison with clonidine. Phytotherapy research. 2009;23(11):1549-1552.

35. Davids LM, Kleemann B, Kacerovská D, Pizinger K, Kidson SH. Hypericin phototoxicity induces different modes of cell death in melanoma and human skin cells. Journal of Photochemistry and Photobiology B: Biology. 2008;91(2-3):67-76.

36. Zou YP, Lu YH, Wei DZ. Protective effects of a flavonoid-rich extract of Hypericum perforatum L. against hydrogen peroxide-induced apoptosis in PC12 cells. Phytotherapy research. 2010;24(S1):S6-S10.

37. Van Strater AC, Bogers JP. Interaction of St John's wort (Hypericum perforatum) with clozapine. Int Clin Psychopharmacol. 2012;27(2):121-124.

38. Borrelli F, Izzo AA. Herb-drug interactions with St John's wort (Hypericum perforatum): an update on clinical observations. The AAPS journal. 2009;11(4):710-727.

39. Lee HH, Ye S, Li XJ, Lee KB, Park MH, Kim SM. Combination treatment with paclitaxel and doxorubicin inhibits growth of human esophageal squamous cancer cells by inactivation of Akt. Oncology reports. 2014;31(1):183-188.

40. Asakura T, Ohkawa K, Takahashi N, Takada K, Inoue T, Yokoyama S. Glutathione-doxorubicin conjugate expresses potent cytotoxicity by suppression of glutathione S-transferase activity: comparison between doxorubicin-sensitive and-resistant rat hepatoma cells. British journal of cancer. 1997;76(10):1333.

41. Clementi ME, Giardina B, Di ES, Mordente A, Misiti F. Doxorubicin-derived metabolites induce release of cytochrome $\mathrm{C}$ and inhibition of respiration on cardiac isolated mitochondria. Anticancer research. 2003;23(3B):2445-2450.

42. Marchand DJ, Renton KW. Depression of cytochrome P-450-dependent drug biotransformation by adriamycin. Toxicology and applied pharmacology. 1981;58(1):83-88.

43. Shibayama Y, Ikeda R, Motoya T, Yamada K. St. John's Wort (Hypericum perforatum) induces overexpression of multidrug resistance protein 2 (MRP2) in rats: a 30-day ingestion study. Food Chem Toxicol. 2004;42(6):995-1002.

44. Smith PF, Bullock JM, Booker BM, Haas CE, Berenson CS, Jusko WJ. Induction of imatinib metabolism by hypericum perforatum. Blood. 2004;104(4):1229-1230.

45. Frye RF, Fitzgerald SM, Lagattuta TF, Hruska MW, Egorin MJ. Effect of St John's wort on imatinib mesylate pharmacokinetics. Clinical Pharmacology \& Therapeutics. 2004;76(4):323-329.

46. Mathijssen RH, Verweij J, de Bruijn P, Loos WJ, Sparreboom A. Effects of St. John's wort on irinotecan metabolism. Journal of the National Cancer Institute. 2002;94(16):1247-1249.

47. Goey AK, Meijerman I, Rosing H, Marchetti S, Mergui-Roelvink M, Keessen M, et al. The effect of St John's wort on the pharmacokinetics of docetaxel. Clinical pharmacokinetics. 2014;53(1):103-110.

48 Spratlin J, Sawyer MB. Pharmacogenetics of paclitaxel metabolism. Critical Reviews in Oncology/Hematolo- 